\title{
Microbial contamination in the operating theatre: a study in a hospital in Baghdad
}

S. Ensayef, ${ }^{1}$ S. Al-Shalchi ${ }^{2}$ and M. Sabbar ${ }^{3}$

$$
\begin{aligned}
& \text { التلوث المكرِ بِي في غُرَف العمليات: دراسة في أحد مستشفيات بغداد }
\end{aligned}
$$

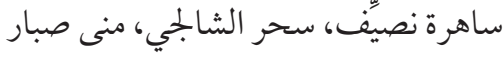

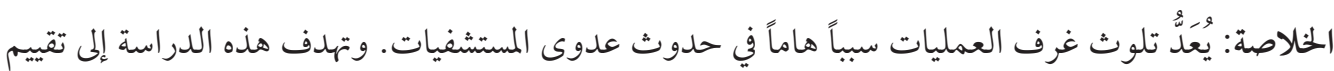

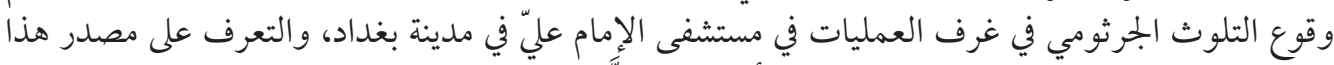

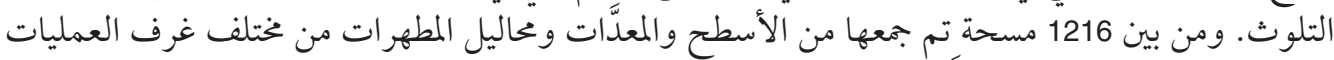

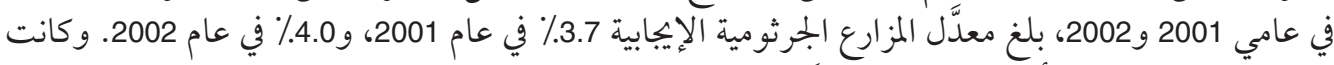

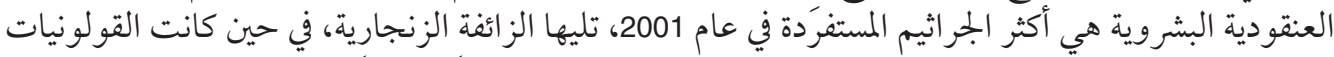

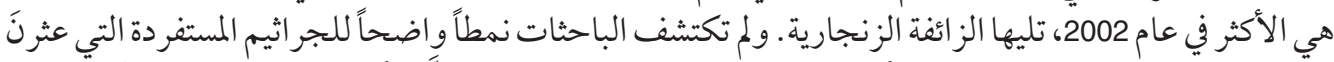

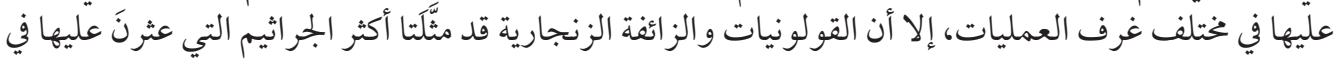
غرف العمليات.

ABSTRACT Contamination of the operating theatre is a major cause of nosocomial infection. This study aimed to evaluate the incidence of bacterial contamination of operating theatres in Al Imam Ali Hospital in Baghdad, and the source of contamination. From 1216 swabs collected from surfaces, equipment and antiseptic solutions from different operating theatres in 2001 and 2002, the rates of positive cultures were $3.7 \%$ in 2001 and $4.0 \%$ in 2002. Staphylococcus epidermidis was the most common isolate in 2001 followed by Pseudomonas aeruginosa, whereas in 2002 coliform bacteria were the highest, followed by $P$. aeruginosa. No clear pattern of isolates was found in different types of operating theatres, although coliforms and $P$. aeruginosa were mostly found in the delivery theatre.

\section{Contamination microbienne dans les salles d'opération : étude dans un hôpital de Bagdad}

RÉSUMÉ La contamination de la salle d'opération est une cause majeure d'infection nosocomiale. Cette étude visait à évaluer l'incidence de la contamination bactérienne des salles d'opération à l'hôpital Al Imam Ali de Bagdad, ainsi que la source de la contamination. Sur 1216 prélèvements recueillis sur les surfaces, matériel et solutions antiseptiques de différentes salles d'opération en 2001 et 2002, le taux de cultures positives était de 3,7\% en 2001 et de 4,0\% en 2002. Staphylococcus epidermidis était l'isolat le plus fréquent en 2001, suivi de Pseudomonas aeruginosa, alors qu'en 2002, les colibacilles étaient les plus répandus, suivis de $P$. aeruginosa. Aucune caractéristique évidente n'a été observée concernant les isolats dans les différents types de salle d'opération, même si les colibacilles et $P$. aeruginosa étaient surtout présents dans la salle d'accouchement.

${ }^{1}$ Department of Biology, College of Science, Al-Mustansiriyah University, Baghdad, Iraq.

${ }^{2}$ Department of Biotechnology, College of Science, Baghdad University, Baghdad, Iraq (Correspondence to S. Al-Shalchi: Saharalshalchi_66@hotmail.com).

${ }^{3}$ Medical Analysis Department, Technical Medical College, Commission of Technical Education, Baghdad, Iraq. Received: 06/11/05; accepted: 08/06/06

المجلة الصحية لشرق المتوسط، منظمة الصحة العالمية، المجلد الخامس عشر، العلد (، 9. ب. 


\section{Introduction}

Contamination of operating theatres is one of the most life-threatening sources of nosocomial infection for patients, especially in transplant surgery, heart surgery, cystoscopy and transurethral resection of prostate and bladder tumours [1]. Multiple reservoirs have been reported as being responsible for hospital contamination, particularly the operating theatre, including unfiltered air, ventilation systems and antiseptic solutions [2]. Other reports suggest that a range of microenvironmental conditions exist even within purified water systems which are intended for laboratory use or for irrigation, leading to variable populations of contaminant bacteria [3]. Medical staff still represent an exogenous contaminant source in operating theatres [4] and personnel move back and forth between the operating theatre and other parts of the hospital without changing their gowns or slippers. Moreover, patients are not consistently cleaned or shaved before coming to the operating theatre. All these factors play a role in contamination of operating theatres and consequent postoperative infections [5].

Many patients are concerned about the risk of postoperative infections, so our study aimed to evaluate the incidence of bacterial contamination of operating theatres in one of the busiest hospitals in Baghdad, Iraq, Al Imam Ali Hospital, and to identify the contaminating agents and their distribution within different theatres.

\section{Methods}

From February 2001 to December 2002, 1216 swabs were taken from 12 operating theatres in Al Imam Ali Hospital: 4 theatres for general surgery, 3 for fractures, 3 for deliveries, 1 for ophthalmic surgery and 1 for ear and nose and throat (ENT) surgery.
Samples were collected 2-3 times monthly with cotton-tipped swabs from the surfaces, equipment and antiseptic solutions within the operating theatres, before and after operations, over the 2-year period. The collection was done by a medical care employee belonging to the central medical laboratory of the Ministry of Health in Iraq.

The swabs obtained were cultured directly in prepared MacConkey and blood agar media (Oxoid, England) by the streaking method, and standard methods of identification were used according to Holt et al. [6] and Baron and Finegold [7]. The inoculated plates were incubated aerobically overnight at $37^{\circ} \mathrm{C}$ for 24 hours, then culture characteristics were examined including colony morphology on culture media, characteristic appearances such as lactose-fermentation, haemolysis, pigmentation, mucous secretion and swarming phenomena. The identifications were confirmed by biochemical tests, including the oxidase test, catalase test, coagulase test, indole test, methyl red test, Voges-Proskauer test and citrate utilization.

\section{Results}

The incidence of positive cultures was $23 / 622$ cultures $(3.7 \%)$ in 2001 and 24/594 $(4.0 \%)$ in 2002.

The monthly distribution of positive cultures showed no clear pattern in different months in any 1 year or between the 2 years (Figure 1), but in general there was a decrease in the incidence of positive cultures in the summer season in both study years.

Identification of bacterial isolates revealed that in 2001 Staphylococcus epidermidis was the most common isolate (39.1\%), followed by Pseudomonas aeruginosa (30.4\%), whereas in 2002 coliform bacteria were the most common isolates 


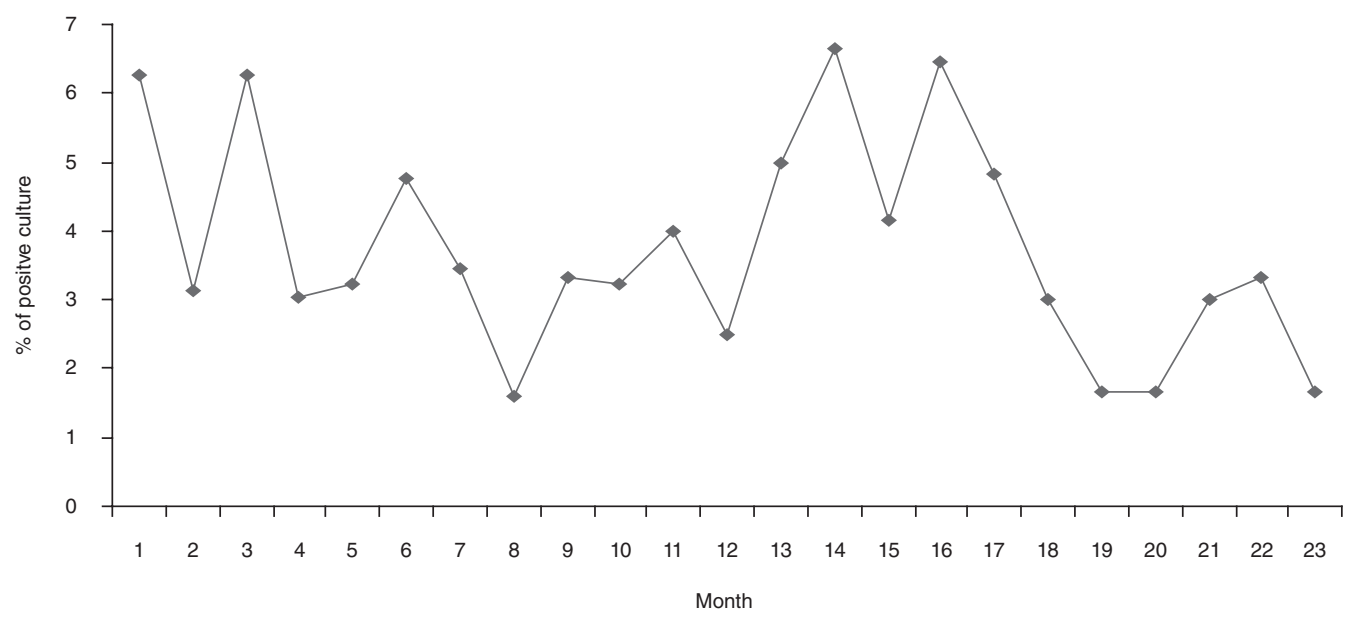

Figure 1 Incidence of positive cultures from total number of samples obtained per month (February 2001 to December 2002)

(62.5\%), followed by P. aeruginosa $(25.0 \%)$ (Table 1).

To demonstrate the possible source of contamination, the distribution of bacterial isolates according to operating theatre were examined. The results showed that in 2001,5 of the S. epidermidis isolates were obtained from fracture operating theatre, 2 from general surgery and 1 isolate each from the ophthalmic and ENT operating theatres (Figure 2). However most $P$. aeruginosa isolates were from the delivery operating theatre. In 2002 the coliform bacteria showed a higher rate among contaminant isolates and, importantly, this species of bacteria was collected from 4 of the 5 types of operating theatre, suggesting a possible outbreak in the hospital from general sources (Figure 2).

Other species of coliform bacteria were found in very low numbers, perhaps due to the carelessness of patients or medical staff.

\section{Discussion}

In 2001 the highest number of contaminant bacteria was for S. epidermidis. In these cases the contaminate source is usually endogenously from normal skin flora of patients or exogenously from surgical staff,

\begin{tabular}{lrrrr}
\hline \multicolumn{5}{l}{ Table 1 Bacteria isolated as a proportion of the total number of positive cultures } \\
\hline Bacterial isolates & \multicolumn{2}{c}{2001} & \multicolumn{2}{c}{$\mathbf{2 0 0 2}$} \\
& No. & $\%$ & No. & $\%$ \\
\hline Staphylococcus epidermidis & 9 & 39.1 & 2 & 8.3 \\
Staphylococcus aureus & 4 & 17.4 & 1 & 4.2 \\
Pseudomonas aeruginosa & 7 & 30.4 & 6 & 25.0 \\
Coliforms & 3 & 13.0 & 15 & 62.5 \\
Total & 23 & 100.0 & 24 & 100.0 \\
\hline
\end{tabular}

المجلة الصحية لشرق المتوسط، منظمة الصحة العالمية، المجلد الخامس عشر، العدد (، 9 ·. 


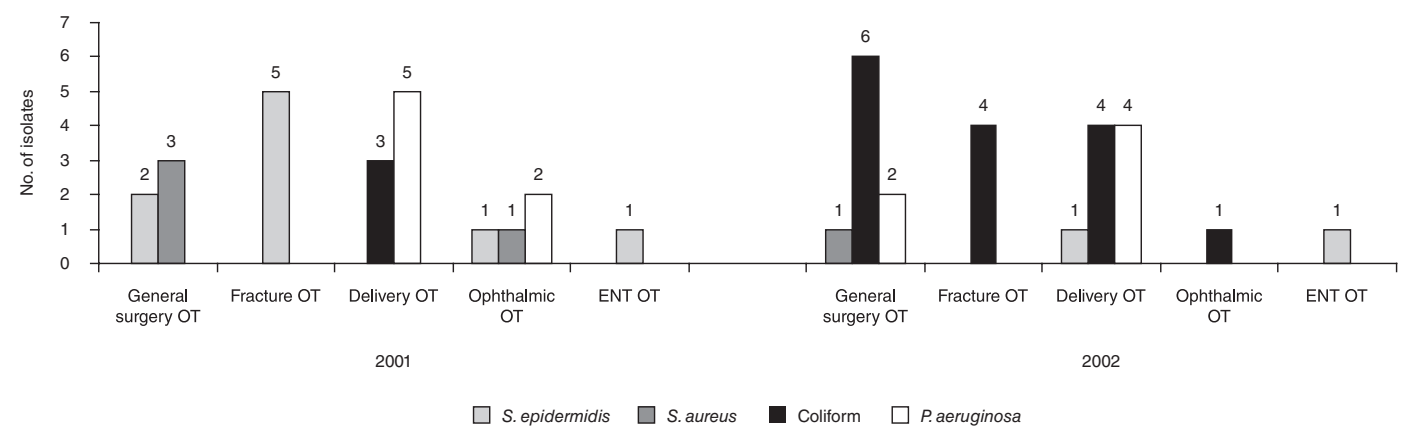

Figure 2 Number and type of isolates identified from the different operating theatres (OT)

especially as $S$. epidermidis was the main infectious agent in the fracture operating theatre [8].

$P$. aeruginosa was the second most common isolate and this may indicate the contaminant source from antiseptic solutions or from breast-fed babies, especially as this bacteria is an opportunistic pathogen that can be found in most moist environments and has a combination of features such as the ability to survive and spread in hospital environments, acquisition of multiple virulence determinants and intrinsic resistance to commonly used antibiotics and disinfectants. This makes $P$. aeruginosa a major lifethreating agent that is responsible for many outbreaks in operating theatres $[9,10]$.

In contrast, coliforms were dominant in 2002. Coliforms are fecal bacteria and this suggests that in this case the food and water supply was the source of contamination. Another possible contaminant source is the bowels of patients, from normal flora or from urinary tract infections, particularly in the delivery theatre as Escherichia coli is the most common infectious agent in pregnant women [11]. Further analysis is needed using advanced techniques such as pulsed field gel electrophoresis or polymerase chain reaction to determine if the overall isolates descend from a single clone or not, especially when isolates are collected from different theatres, as this will be a good indication of whether there is a general outbreak or not $[10,12]$.

The results indicate that 3 factors need to be considered. First, some bacterial strains such as $S$. aureus, $S$. epidermidis, E. coli and $P$. aeruginosa have a greater propensity to cause contamination, especially in operating theatres, so extensive infection control practices are necessary to prevent or contain these pathogens.

Second, the social level of incoming patients reflects the individual patient risk, which must be investigated and modified whenever possible. The patient should be prepared for operation and appropriate skin antiseptic should be used on the operation sites; the patient should also be considered for preoperative antibiotic prophylaxis. Bowel preparation, if appropriate, should be carried out.

Third, careful attention to the theatre operating environment is important, especially to avoid airborne transmission of bacteria and transmission to the water supply and food; surgical expertise and theatre discipline are essential components against surgical sepsis.

In conclusion, there was no clear pattern in the incidence in different months during 
the period of study although there was tendency towards decreased incidence of positive cultures in the summer season. The most common contaminant species found in the different operating theatres (S. epidermidis,
E. coli and $P$. aeruginosa) had some relation to the kind of operation. This may indicate that sterilization methods are not efficient in our operating theatres and are putting patients at risk of postoperative infections.

\section{References}

1. Madsen $\mathrm{PO}$, Larsen $\mathrm{EH}$, Dorflinger $\mathrm{T}$. Infectious complications after instrumentation of urinary tract. Urology, 1985, 26(1):1517.

2. Fridkin SK, Jarvis WR. Epidemiology of nosocomial fungal infection. Clinical microbiology reviews, 1996, 9:499-511.

3. McFeters GA et al. Distribution of bacteria within operating laboratory water purification system. Applied and environmental microbiology, 1993, 59(5):1410-5.

4. Emmerson M. A microbiologist's view of factors contributing to infection. New horizons (Baltimore, Md.), 1998, 6(2 Suppl.):S3-10.

5. Siddiqui AR, Luby SP. High rates of discitis following surgery for prolapsed intervertebral discs at a hospital in Pakistan. Infection control and hospital epidemiology, 1998, 19(7):526-9.

6. Holt JG et al., eds. Manual of determination bacteriology, 9th ed. USA, Williams and Wilkins, 1994.

7. Baron E, Finegold SM. Bailey and Scott's diagnostic microbiology, 8th ed. Baltimore, Mosby, 1990.
8. Gravin $\mathrm{KL}$ et al. Infection after total hip arthroplasty. Journal of bone and joint surgery, 1995, 77A:1576-88.

9. Bellido F, Hancock R. Susceptibility and resistance of $P$. aeruginosa to antimicrobial agents. In: Campa M, Bendinelli M, Friedman $\mathrm{H}$, eds. Pseudomona aeruginosa as an opportunistic pathogen. New York, Plenum Press, 1993:321-48.

10. Pena $\mathrm{C}$ et al. An outbreak of carbapenemresistant Pseudomona aeruginosa in a urology ward. Clinical microbiology and infection, 2003, 9:938-43.

11. McNicholas MM, Griffin JF, Cantwell DF. Ultrasound of the pelvis and renal tract combined with a plain film of abdomen in young women with urinary tract infection: can it replace intravenous urography? A prospective study. British journal of radiology, 1991, 64:221-4.

12. Diaz-Guerra TM et al. Genetic similarity among one Aspergillus flavus strain isolated from a patient who underwent heart surgery and two environmental strains obtained from the operating room. Journal of clinical microbiology, 2000, 38(6):241922. 